\title{
CURRENT SURVEY OF PERIODICALS
}

\section{ACTA SLAVICA IAPONICA}

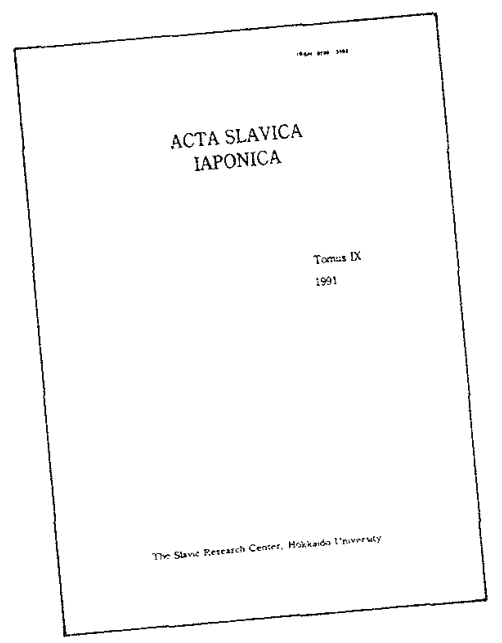

ACTA SLAVICA IAPONICA (ASI) is an annual journal published by the Slavic Research Center (SRC) since 1983. The primary aim of this journal is to introduce Japanese scholarship on Russian/Soviet and East European studies. All articles are published in European languages.

In accordance with the interdisciplinary character of SRC, articles published in ASI vary in their orientation. In terms of discipline, among thirtytwo articles form the last three issues, nine were on international relations, seven on economies, five on literature, four on history, most of them were characterized by their interdisciplinary approarch. Several issues in the past have been designed to present forums on specific topics relating to joint research programs of SRC. For instance, Volume 2 (1984) was entirely dedicated to the problem of "Order Orientation and Liberal Tendencies in Soviet and East European Societies", Volume 5(1987) to the topic: "The Soviet Union Faces Asia: Perceptions and Policies", while 7 of the 13 articles in Volume 9(1991) dealt with Japanese-Russian-Soviet relations.

ASI also publishes bibliographical information about major holdings of Japanese research institutions as well as reviews of outstanding books in Japanese on Russian/Soviet and East European studies.

Although ASI is a journal of SRC, contributions from outside are welcome so long as their publications contribute to the development of Japanese Slavic studies.

(Editorial office of both journals: Slavic Research Center, Hokkaido University, Kita-9 Nishi-7, Kita-ku, Sapporo 060)

(Tetsuo MOCHIZUKI) 